\title{
Cognitive Pragmatic Rehabilitation Program in Schizophrenia: A Single Case fMRI Study
}

\author{
Ilaria Gabbatore, ${ }^{1,2}$ Francesca M. Bosco, ${ }^{2,3,4}$ Elisabetta Geda, ${ }^{5}$ Luigi Gastaldo, ${ }^{6}$ Sergio Duca, ${ }^{7}$ \\ Tommaso Costa, ${ }^{3,7}$ Bruno G. Bara, ${ }^{2,3,4}$ and Katiuscia Sacco ${ }^{3,4,5}$ \\ ${ }^{1}$ Faculty of Humanities, Research Unit of Logopedics, Child Language Research Center, University of Oulu, Oulu, Finland \\ ${ }^{2}$ Center for Cognitive Science (CSC), University and Polytechnic of Turin, Turin, Italy \\ ${ }^{3}$ Department of Psychology, University of Turin, Turin, Italy \\ ${ }^{4}$ Neuroscience Institute of Turin, Turin, Italy \\ ${ }^{5}$ Brain Imaging Group (BIG), Koelliker Hospital, Turin, Italy \\ ${ }^{6}$ Psychiatric Service, Mental Health Department, ASL-TO3, Turin, Italy \\ ${ }^{7}$ CCS FMRI, Koelliker Hospital, Turin, Italy
}

Correspondence should be addressed to Francesca M. Bosco; francesca.bosco@unito.it

Received 20 July 2016; Revised 4 November 2016; Accepted 7 December 2016; Published 23 January 2017

Academic Editor: Preston E. Garraghty

Copyright (C) 2017 Ilaria Gabbatore et al. This is an open access article distributed under the Creative Commons Attribution License, which permits unrestricted use, distribution, and reproduction in any medium, provided the original work is properly cited.

\begin{abstract}
Introduction. The present study was intended to evaluate the effects of a rehabilitative training, the Cognitive Pragmatic Treatment $(\mathrm{CPT})$, aimed at improving communicative-pragmatic abilities and the related cognitive components, on the cerebral modifications of a single case patient diagnosed with schizophrenia. Methods. The patient underwent two functional magnetic resonance imaging (fMRI) sessions, before and after the treatment. In order to assess brain changes, we calculated the Amplitude of Low Frequency Fluctuation (ALFF) index of the resting-state fMRI signal, which is interpreted as reflecting the intensity of the spontaneous regional activity of the brain. Behavioural measures of the patient's communicative performance were also gathered before and after training and at follow-up. Results. The patient improved his communicative performance in almost all tests. Posttraining stronger ALFF signal emerged in the superior, inferior, and medial frontal gyri, as well as the superior temporal gyri. Conclusions. Even if based on a single case study, these preliminary results show functional changes at the cerebral level that seem to support the patient's behavioural improvements.
\end{abstract}

\section{Introduction}

Communicative-pragmatic ability is a typically impaired feature in schizophrenia [1]. Communicative-pragmatic refers to the ability to use language and nonverbal expressive means, such as gestures and facial expressions, and to convey meaning in a given context [2]. Despite their almost intact syntactic ability [3], patients with schizophrenia show difficulties in a more complex use of language, that is, pragmatic [4]. They show poor performance in comprehending different kinds of pragmatic phenomena, such as indirect speech acts [5], deceit [6], irony [7], and metaphoric expression [8], and in recognizing and recovering communicative failures [9]. Moreover, schizophrenia implies deficits in the management of conversation [10], narrative impairments [11], and poor performance in nonverbal expressiveness [12] and in emotional prosody (see [13]). A broad assessment provided using the Assessment Battery for Communication (ABaCo) [14-16] has recently given an articulated description of communicative-pragmatic deficit in patients with schizophrenia [17]. Results of the study showed that patients have difficulties in using linguistic, extralinguistic, and paralinguistic expressive modalities both in the comprehension and in the production of various types of pragmatic tasks, as direct and indirect speech acts, irony and deceit. According to some authors (e.g., [18]) these deficits are related to the well-demonstrated theory of mind (ToM; [19]) impairment of these patients (e.g., [20, 21]). However, there is evidence in the literature to suggest that ToM is not able, alone, to fully explain the communicative deficits of these patients [9]. 
Pragmatic ability is something which is articulated and requires a broad interplay of processes that seem to involve several prefrontal, frontal, and temporal networks, even though the identification of specific neural substrates underlying this competence is quite complicated. Shibata et al. [22] investigated the neural substrates of irony comprehension, showing higher activation in the right medial prefrontal cortex and right precentral and left superior temporal sulcus. More recently, Akimoto et al. [23] highlighted the complexity of the neural correlates involved in the comprehension of irony. The authors identified the right anterior superior temporal gyrus as being associated with the representation of social conceptual knowledge, while the medial prefrontal cortex and the right anterior inferior temporal gyrus could be involved in the understanding of context. Uchiyama et al. [24], in an fMRI study, investigated the ability to distinguish between literal and intended meaning in understanding metaphor and sarcasm. The authors found metaphor-specific activation in the head of the caudate and sarcasm-specific activation in the left amygdala. Furthermore, both metaphor and sarcasm activated the anterior rostral medial frontal cortex. The authors concluded that these areas are jointly involved in monitoring the coherence of literal meaning of the utterance and in mentalizing within social contexts in order to understand the pragmatic-communicative meanings of an utterance.

Data in the literature show that cognitive and communicative impairments may restrict the possibilities for functional recovery and can persist also after the psychosis subsides (e.g., [25, 26]); moreover, individuals with schizophrenia seem to be able to improve their cognitive and social cognitive abilities following behavioural training [27]. Despite this evidence, little attention has been given to cognitive remediation in schizophrenia. Some authors have developed remediation programs to improve social functioning [28] and to affect recognition [29], awareness, motivation and social competencies [30], metacognition [31], and theory of mind [32].

We recently designed the Cognitive Pragmatic Treatment (CPT), an integrated treatment specifically focused on the remediation of communicative-pragmatic abilities and related cognitive components. It offers the participants the opportunity to train their own ability to manage communicative interchanges using different communicative means, that is, language and gestures and appropriate paralinguistic cues, and adhering to the social and conversational settings where the communicative interaction takes place. Additionally, the CPT focuses on components such as awareness, theory of mind, and executive functions, which play a role $[11,33]$ in structuring efficient communication. The training has already been used with TBI individuals [34, 35] and in a pilot study with patients with schizophrenia [36], revealing high rates of effectiveness in improving their communicative performance.

A training program is aimed at restructuring cerebral functioning. To measure brain changes in response to practice, functional magnetic resonance imaging (fMRI) has proven to be an excellent tool. It has been used to explore the cerebral mechanisms underlying specific training programs, with both healthy and clinical individuals in several domains. In as much as what concerns schizophrenic individuals, a recent review [37] summarized the studies which evidenced brain plasticity through neuroimaging. More specifically, what kind of changes could be expected in these patients after training of their communicative abilities? In recent years, alterations in neural oscillations have been identified as a potential mechanism involved in the pathophysiology of schizophrenia, able to explain cognitive dysfunctions and certain symptoms of this illness (for a review, see [38]). In particular, alterations in the Amplitude of Low Frequency Fluctuation (ALFF) have been found in adult patients with schizophrenia [39], in adolescents with early onset [40, 41], and, to a lesser extent, in adolescents and young people at high clinical psychotic risk [41]. Besides, these alterations covary with cognitive deficits [42], suggesting that the ALFF relates to symptoms and can predict an onset of schizophrenia. In a rehabilitation perspective, changes of the ALFF index can then give an indication of the cerebral mechanisms accompanying recovery. On the basis of these, we tested the effectiveness of the CPT on a single chronic patient with a diagnosis of schizophrenia. In particular we assessed the ALFF index before and after the CPT: the aim was to investigate the existing relationship between the behavioural improvements due to the training and the cerebral changes in functional activity. We hypothesized a posttreatment reorganization of regions involved in communication: this would indicate that CPT can favor brain plasticity towards improvement. To the best of our knowledge, there are no studies assessing the effectiveness of a specific training for the communicativepragmatic abilities in patients with schizophrenia, using a functional brain activity measure.

\section{Material and Methods}

2.1. Profile of the Patient. Patient S.T., a 39-year-old male, right handed, with a high-school diploma as electronics technician (13 years of education), has been recruited from the Department of Mental Health (DSM-To2) in Turin. He had a diagnosis of paranoid schizophrenia, made by a qualified clinician belonging to the clinical unit, using DSMIV criteria. S.T. had lived for a few years in a therapeutic center, that is, a health care structure where people with several kinds of intellectual and psychiatric disorders live with the constant help and assistance of qualified staff such as nurses, professional educators, and psychologists. Nevertheless, at the moment of the study he used to live in sheltered accommodation in Turin, a housing arrangement where a small group of people with similar therapeutic conditions live together receiving assistance from specialized health workers for just a few hours per week; moreover, he was included in a supported employment program, under the supervision of the local mental health care unit. The symptomatology of the patient at the time of the first assessment was investigated with the Positive and Negative Syndrome Scale (PANSS; [43]). The PANSS was completed by a qualified psychiatrist and reported 15 scores at the negative symptoms scale, 15 scores at the positive symptoms scale, and 36 scores at the general symptoms scale (PANSS total score: 66). S.T. was 


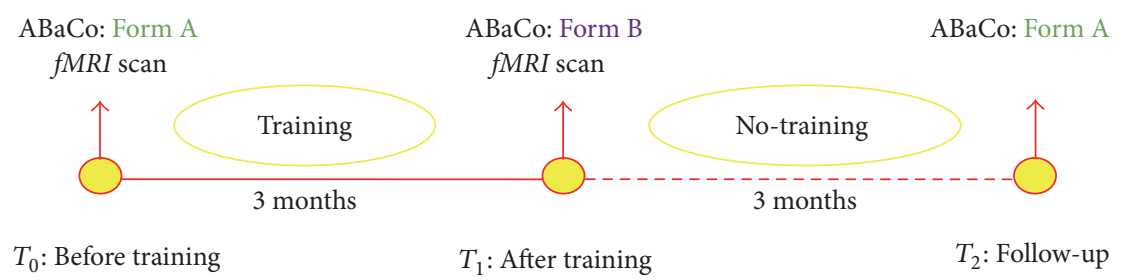

FIgURE 1: Graphical representation of the experimental design.

treated with atypical antipsychotics (risperidone), anxiolytics (chlordesmethyldiazepam), and sedative drugs aimed at sleep regulation (flurazepam).

At the moment of the study, S.T. was in the chronic phase of the illness. He demonstrated adequate cognitive skills tested by the achievement of a cut-off score of 24/30 at Mini Mental State Examination (MMSE; [44]). He had communicative-pragmatic deficits, as resulting from the administration of form A of the Assessment Battery for Communication ( $\mathrm{ABaCo}$; $[45])$ in comparison to normative data of $\mathrm{ABaCo}$ [46]. He attended all the training sessions. He did not suffer from anxiety disorders such as claustrophobia or panic attacks or any disorders which could be catastrophically exacerbated by confined spaces, such as MRI. Moreover, the patient met predefined exclusion criteria referring to absence of leucotomy, neurological disability, and alcohol or drug addiction. S.T. was informed about the procedure and the features of the exam and he gave his informed written consent for the rehabilitative treatment, the behavioural assessment, and the fMRI scanning. The study was approved by the BioEthics Committee of the University of Turin.

2.2. Experimental Design. The study comprised a threemonth training period and three experimental sessions, organized according to an ABA design as described in Figure 1.

2.2.1. T0: Before Training. The patients' communicative abilities were assessed immediately before the beginning of the rehabilitation program, through the equivalent form $\mathrm{A}$ of $\mathrm{ABaCo}$.

2.2.2. T1: After Training. After completing the training program, form $\mathrm{B}$ of the $\mathrm{ABaCo}$ was administered to assess the efficacy of the training on the communicative abilities of the participants.

2.2.3. T2: Follow-Up. In order to assess the stability of the patients' performance in time, form $\mathrm{A}$ of the $\mathrm{ABaCo}$ was administered again three months after the rehabilitation program.

2.3. The Cognitive Pragmatic Treatment. The patient took part in the CPT [47], and he underwent the fMRI scanning before and after treatment. The CPT lasted 10 weeks and it was structured in two sessions per week, each one lasting 90 minutes. Patients attended the sessions in small groups of five/six, led by a psychologist. The treatment mainly concentrated on the different expressive modalities of communication, that is, linguistic, extralinguistic, paralinguistic, social appropriateness, and conversational abilities. Moreover, other sessions were focused on aspects such as awareness, theory of mind, and planning, which have been shown to have a role to play in communicative performance [45-47]. The training provided the patients with an ecological setting where they were encouraged to exercise their communicative abilities and learn how to face typical situations of everyday interactions; this goal was realized through self-monitoring strategies and feedback provided by the therapist.

Communicative-pragmatic difficulties displayed by patients with schizophrenia are related to their difficulties in filling the gap between what is literally said and what is meant, as, for example, in indirect speech acts and figurative language (e.g., [17]). For this reason, many activities along the training were focused on the understanding of the partner's intended meaning starting from the expressed literal message. Specific attention was also given to the ability to interpret and use nonverbal and paralinguistic cues, such as facial expression and the tone of voice, in order to identify the correct speaker's communicative intention; irony, for example, is characterized by specific paralinguistic cues [48] that help a person to distinguish it from deceit. Moreover, frequently these patients have difficulty in modulating their speech according to the contextual information. This is the reason why many activities of the training were focused on the ability to decode violations of the conversational implicatures and to avoid digressions and derailments. An overview of each session is provided in Table 1. See also $[34,36]$ for a detailed explanation of CPT.

2.4. Behavioural Measures. The communicative-pragmatic abilities of the patient were measured through the administration of the equivalent forms of $\mathrm{ABaCo}$ [16] before and after treatment. The equivalent forms of the $\mathrm{ABaCo}$ have shown a good internal consistency, a good correlation between forms, and an excellent interrater agreement $[15,16]$. They are comprised of four evaluation scales, that is, linguistic, extralinguistic, paralinguistic, and context, aimed at assessing the main pragmatic components of communication. Each scale is divided into two subscales, evaluating, respectively, comprehension and production abilities in each communication modality. A detailed description of the clinical tool, the procedure, and the scoring criteria is provided in [16]; see also [49].

2.5. fMRI Procedures. In order to investigate whether any changes in functional brain activity were detectable after $\mathrm{CPT}$, we used a resting-state paradigm (rs) for imaging data. 
TAble 1: Structure of the Cognitive Pragmatic Treatment: topics, material, and procedures belonging to each session.

\begin{tabular}{|c|c|c|}
\hline Session (s) & Topic & Material and procedure \\
\hline n. 1 & $\begin{array}{l}\text { Awareness of one's own } \\
\text { difficulties }\end{array}$ & $\begin{array}{l}\text { Construction of the clinical setting and introduction of aims and } \\
\text { tools of the CPT. Video-recording of the self-presentation of each } \\
\text { patient (own communicative difficulties and expectations). }\end{array}$ \\
\hline n. 2 & $\begin{array}{l}\text { General communicative } \\
\text { ability: an overview }\end{array}$ & $\begin{array}{l}\text { Videos and role playing tasks focused on the overall pragmatic } \\
\text { effectiveness expressed through all the modalities constituting the } \\
\text { communicative competence. }\end{array}$ \\
\hline $\begin{array}{l}\text { n. } 3 \\
\text { n. } 4\end{array}$ & Linguistic ability & $\begin{array}{l}\text { Videos and role playing tasks based on the linguistic expressive } \\
\text { modality. }\end{array}$ \\
\hline $\begin{array}{l}\text { n. } 5 \\
\text { n. } 6\end{array}$ & Extralinguistic ability & $\begin{array}{l}\text { Videos and role playing tasks based on the gestural expressive } \\
\text { modality. }\end{array}$ \\
\hline $\begin{array}{l}\text { n. } 7 \\
\text { n. } 8 \\
\text { n. } 9\end{array}$ & Paralinguistic ability & $\begin{array}{l}\text { Videos, role playing tasks, and interactive activities specifically } \\
\text { focused on facial expression recognition, rhythm, and tone of the } \\
\text { voice. }\end{array}$ \\
\hline $\begin{array}{l}\text { n. } 10 \\
\text { n. } 11\end{array}$ & $\begin{array}{l}\text { Social appropriateness } \\
\text { ability }\end{array}$ & $\begin{array}{l}\text { Videos and role playing tasks focused on social appropriateness and } \\
\text { communicative adequacy in different contexts. }\end{array}$ \\
\hline $\begin{array}{l}\text { n. } 12 \\
\text { n. } 13\end{array}$ & Conversational ability & $\begin{array}{l}\text { Videos, role playing tasks, and tangram exercises focused on the use } \\
\text { of conversational rules (i.e., turn-taking and management of the } \\
\text { topic). }\end{array}$ \\
\hline n. 14 & $\begin{array}{l}\text { Management of } \\
\text { conversation at the phone }\end{array}$ & $\begin{array}{l}\text { Audio-taped telephone conversation and role playing tasks } \\
\text { specifically focused on telephone conversational rules (i.e., with no } \\
\text { possibility of taking advantage of the paralinguistic and gestural } \\
\text { elements which usually connote communicative interactions). }\end{array}$ \\
\hline n. 15 & Planning ability & $\begin{array}{l}\text { Individual and group activities focused on subgoals tasks (e.g., } \\
\text { planning household chores). }\end{array}$ \\
\hline $\begin{array}{l}\text { n. } 16 \\
\text { n. } 17\end{array}$ & Theory of mind & $\begin{array}{l}\text { Videos and role playing tasks focused on the ability to formulate } \\
\text { metarepresentations with respect to one's own and others' mental } \\
\text { states. }\end{array}$ \\
\hline n. 18 & Narrative ability & $\begin{array}{l}\text { Description tasks and speech elicitation tasks focused on the ability to } \\
\text { tell a story or describe a situation in a proper and clear way. }\end{array}$ \\
\hline n. 19 & $\begin{array}{l}\text { General communicative } \\
\text { ability: a summing-up }\end{array}$ & $\begin{array}{l}\text { Videos and role playing tasks focused on the overall pragmatic } \\
\text { effectiveness expressed through all the modalities constituting } \\
\text { communicative competence. }\end{array}$ \\
\hline n. 20 & Posttraining awareness & $\begin{array}{l}\text { Conclusions and feedback about the results gained by every } \\
\text { participant when compared to the initial video-recorded } \\
\text { performance. }\end{array}$ \\
\hline
\end{tabular}

The results obtained in the pre- and posttreatment phases at the rs-fMRI analyses have been compared, in order to establish the presence of objective effects of rehabilitation at the neuronal level. Data acquisition was performed at the Koelliker Hospital in Turin. Besides the rs scanning (18 minutes), a set of anatomical MRI images were acquired (10 minutes). The patient was instructed to lie on the scannerbed and simply keep his eyes closed, thinking of nothing in particular, and not to fall asleep.

Data acquisition was performed on a 1.5-T Philips Intera with a Sense high-field high-resolution head coil (MRIDC) optimized for functional imaging. Functional T2-weighted images were acquired using echo planar imaging (EPI) sequences, with a repetition time (TR) of $3000 \mathrm{~ms}$, an echo time (TE) of $60 \mathrm{~ms}$, and a $90^{\circ}$ flip angle. The acquisition matrix was $64 \times 64$; the field of view $(\mathrm{FoV})$ was $256 \mathrm{~mm}$. For each paradigm, a total of 100 volumes were acquired. Each volume consisted of 25 axial slices, parallel to the anteriorposterior (AC-PC) commissure line and covering the whole brain; the slice thickness was $4 \mathrm{~mm}$ with a $0.5 \mathrm{~mm}$ gap. At the beginning of functional scanning, two scans were added, and their data was discarded, in order to reach a steady-state magnetization before acquisition of the actual experimental data. In the same session, a set of three-dimensional highresolution T1-weighted structural images was acquired for each participant. This data set was acquired using a Fast Field Echo (FFE) sequence, with a repetition time (TR) of $25 \mathrm{~ms}$, the shortest echo time (TE), and a $30^{\circ} \mathrm{flip}$ angle. The acquisition matrix was $256 \times 256$; the field of view (FoV) was $256 \mathrm{~mm}$. The set consisted of 160 sagittal contiguous images 
TABLE 2: Scores obtained by S.T. at the subscales of $\mathrm{ABaCo}$ at $\mathrm{T} 0$, before training, $\mathrm{T} 1$, after training, $\mathrm{T} 2$, follow-up, and normative values.

\begin{tabular}{|c|c|c|c|c|}
\hline ABaCo subscales & Mean (DS) normative sample ${ }^{\mathrm{a}}$ & T0, before training & T1, after training & T2, follow-up \\
\hline \multicolumn{5}{|l|}{ Comprehension } \\
\hline Linguistic & $.90(.09)$ & 1 & 1 & 1 \\
\hline Extralinguistic & $.81(.13)$ & .88 & 1 & 1 \\
\hline Paralinguistic & $.89(.09)$ & .67 & .83 & 1 \\
\hline Context & $.87(.12)$ & .50 & 1 & 1 \\
\hline \multicolumn{5}{|l|}{ Production } \\
\hline Linguistic & $.90(.09)$ & .81 & 1 & 1 \\
\hline Extralinguistic & $.86(.11)$ & .50 & 1 & 1 \\
\hline Paralinguistic & $.98(.04)$ & 1 & 1 & 1 \\
\hline Context & $.94(.11)$ & 1 & 1 & 1 \\
\hline
\end{tabular}

Note. ${ }^{\mathrm{a}}$ Means and standard deviation of the scores at $\mathrm{ABaCo}$ obtained by a group of healthy individuals with the same characteristics in terms of age and education level as S.T., that is, normative group ranging in age between 35 and 54 years, 13 years of education (see [15]).

covering the whole brain. The in-plane resolution was $1 \times$ $1 \mathrm{~mm}$ and slice thickness was $1 \mathrm{~mm}(1 \times 1 \times 1 \mathrm{~mm}$ voxels $)$.

The functional data of each subject underwent the following preprocessing steps: (1) mean intensity adjustment to prevent global signal variability; (2) slice scan time correction, using a sinc interpolation algorithm; (3) 3D motion correction: all of the volumes were aligned spatially to the first volume by rigid body transformations, using a trilinear interpolation algorithm. The subject's slice-based functional scans were coregistered to their 3D high-resolution structural scan, and the 3D structural data set was transformed into Talairach space [50]. Using the anatomical-functional coregistration matrix and the determined Talairach reference points, we transformed the functional time course into Talairach space and created the volume time course. Afterwards, the temporal series of each voxel have been filtered by a bandpass filtering $(0.01<f<0.08 \mathrm{~Hz})$ in order to remove both the very low frequencies and the noise due to high frequencies (respiratory and cardiac frequencies). Then the filtered time series have been transformed into a frequency domain with the Fourier transformation; this process allows decomposing a signal made of more frequencies and identifying the spectrum of the signal. The power spectrum represents the energy of the signal at different frequencies. We then calculated the Amplitude of Low Frequency Fluctuation (ALFF) index of the resting-state fMRI signal that is based on the amplitude of the low frequency fluctuations of the rs-fMRI signal and it is interpreted as reflecting the intensity of the spontaneous regional activity of the brain. The ALFF index was obtained calculating the square root of the power spectrum between 0.01 and $0.08 \mathrm{~Hz}$, and it represents the average amplitude of the signal in a single voxel. In order to examine the difference between the neuronal activation before treatment and that after treatment, the functional map obtained before treatment was subtracted from that obtained after treatment, using a statistical threshold of $p<0.05$, corrected for multiple comparisons using false discovery rate correction [51].

The script used for the analyses produces specific output able to show Brodmann areas and the cerebral gyri and sulci implicated in the functional activity changes.

\section{Results}

3.1. Clinical and Behavioural Outcome. The scores obtained by S.T. at the equivalent forms of $\mathrm{ABaCo}$, before and after training, are displayed in Table 2, in order to get an overview of the improvement of S.T. after the rehabilitative program. The scores obtained at T0 (before training), T1 (after training), and T2 (follow-up) are compared with the means of the scores obtained at the subscales of $\mathrm{ABaCo}$ by the normative group with the same age and education level as S.T. [15]. As shown in the table, S.T. improved his communicative performance in all the scales of $\mathrm{ABaCo}$, reaching in many cases the normative performance for his age and education level.

3.2. fMRI Outcome. Posttraining stronger activation emerged within the superior, inferior, and medial frontal gyri, as well as the superior temporal gyri. See Figure 2.

\section{Discussion and Conclusion}

The aim of the present study was to evaluate the effect of a rehabilitative training, the $\mathrm{CPT}$, focused on improving communicative-pragmatic ability and on the cerebral functional changes of a single case patient (S.T.) with schizophrenia.

As to what concerns behavioural data, the scores obtained by S.T. at the equivalent forms of $\mathrm{ABaCo}$ [16] before and after training were compared with the normative values of the battery for patient's age and education level [15]. S.T.s performance was initially under the range of normative values in a number of $\mathrm{ABaCo}$ subscales, that is, linguistic and extralinguistic production subscales and paralinguistic and context comprehension subscales. After the CPT, S.T. improved his performance in all the subscales of $\mathrm{ABaCo}$, reaching in the majority of the cases the normative level. The only exception was represented by the paralinguistic comprehension subscale, in which S.T. improved the pretraining performance, even though the obtained score was still under the normative range. A three months' follow-up testified that S.T.s improvement persisted during this time. 

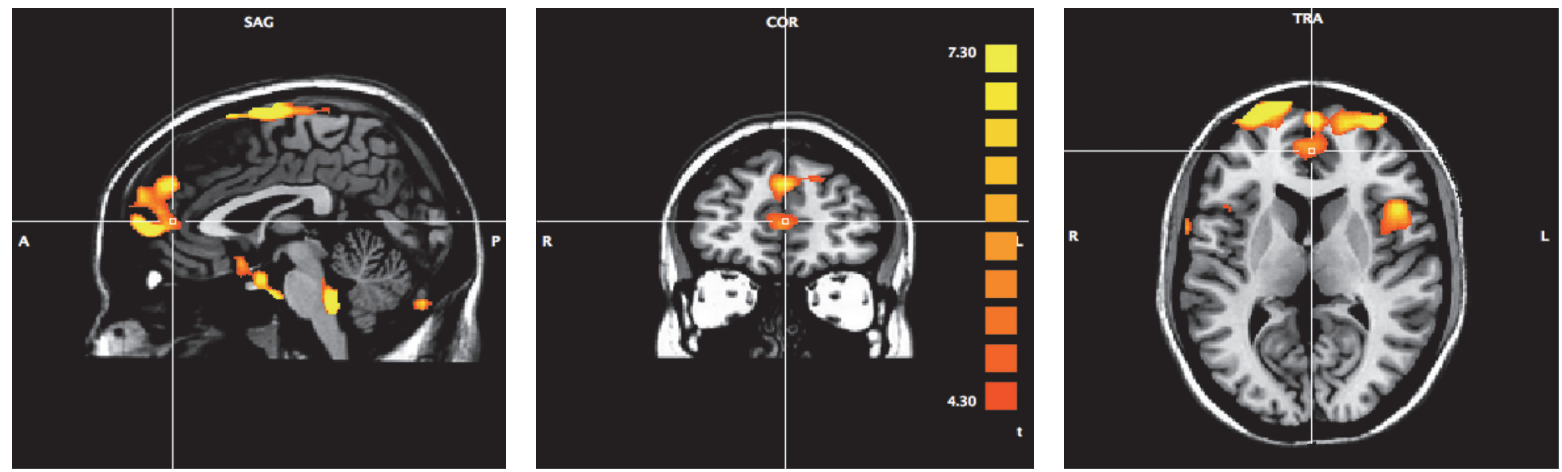

Localization (Brodmann area)

Right hemisphere

Left hemisphere

$t$ value Talairach coord.

$t$ value Talairach coord.

(i) Bilateral superior frontal gyrus (11)

1.634

$-3$

$58-12$

Bilateral medial frontal gyrus (10)

Bilateral inferior frontal gyrus (47)

(ii) Bilateral superior temporal gyrus (22)

$\begin{array}{lll}-55 & 12 & -6\end{array}$

Figure 2: Patient R.M., post- minus pretreatment changes computed as the ALFF index. Talairach coordinates of local maxima of structures showing significant activity ( $p<0.05$, corrected for multiple comparisons). The amount of increase in the ALFF between sessions for the two clusters was $45 \%$ and $29 \%$, respectively.

Posttraining stronger activation emerged in the superior, inferior, and medial frontal gyri, as well as in the superior temporal gyri. In a study by Kircher et al. [52], the inferior frontal gyrus and the right middle temporal gyrus have been found to be involved in schizophrenic patients' impairment in understanding the figurative aspects of language, especially metaphors. Analogous results have been found by Rapp et al. [53], Eviatar and Just [54], and Shibata et al. [55, 56] who showed the involvement of the left inferior frontal cortex (BA 45,47) and of the left medial frontal cortex (BA 10) in processing metaphoric sentences. [52] suggested that the particular activation of these areas might reflect semanticinferencing processes and that dysfunctions at this level might explain deficits in metaphor comprehension in clinical populations such as patients with schizophrenia. Moreover, the superior frontal gyrus is partially responsible for the control of executive functions and has been demonstrated to show abnormalities in schizophrenic individuals [57]. Moreover, Wang et al. [58] found the involvement of the medial frontal areas (BA 10) in the processing of ironic statements, suggesting that this recruitment could be related to the integration of the meaning conveyed by facial expressions and tone of the voice with the comprehension of the speaker's intention. Regarding discourse organization, [59] found activation in middle and superior frontal regions of the right hemisphere in discourse processing and [60] highlighted that the medial frontal regions have a role in the coherence processes in language comprehension and in establishing pragmatic connection between presented sentences. The medial frontal cortex has been found, also, to be involved in pragmatic comprehension tasks related to plausibility judgment [61] and reasoning [62]. Moreover, it seems to have a role in the evaluation of the emotional significance of the external stimuli and in mentalization processes [63], which are often impaired in schizophrenia and which have been trained during the rehabilitative sessions. Finally, regarding the modification in the superior temporal gyrus, Kuperberg et al. [64] found an involvement of this area in the elaboration of sentences which violated semantic restrictions. Moreover, Wildgruber et al. [65] indicated a broad pattern of activation related to the evaluation of linguistic and emotional aspects of speech intonation, including the prefrontal and the superior temporal cortex, that could be interpreted as related to R.M.'s training on the paralinguistic aspects of communication. It is interesting to note that our results are in line with those of a meta-analysis [66] on fMRI studies focused on nonliteral language, in terms of metaphors, proverbs, idioms, irony, and sarcasm. The authors identified a common network for nonliteral language, including left and right inferior frontal gyrus and left middle and superior temporal gyrus with contributions from medial prefrontal and superior frontal regions.

Globally considered, the detected brain modifications seem to support the behavioural improvements the patient obtained on $\mathrm{ABaCo}$ scales. Indeed, particular emphasis during the training has been given to the ability to go beyond the literal message of an utterance and to correctly understand the speaker's meaning. However, since this is a single case study, the results should be interpreted with caution and further research on convenience samples is necessary to confirm the findings and extend them to present as well as other clinical populations. 


\section{Disclosure}

Ilaria Gabbatore and Francesca M. Bosco are co-first authors.

\section{Competing Interests}

The authors declare that there is no conflict of interests regarding the publication of this paper.

\section{Authors' Contributions}

Ilaria Gabbatore and Francesca M. Bosco equally contributed to the realization of the paper. Ilaria Gabbatore took care of the recruitment process and the assessment procedures before and after training. She is responsible for the Methods section of the paper and she wrote the first draft of the discussion section concerning the interpretation of the findings. Francesca M. Bosco took care of the management of the rehabilitative sessions and supervised the entire project. She is also responsible for the introductive part of the paper focused on the review of the literature concerning pragmatic impairment in schizophrenia. Elisabetta Geda run the fMRI data analyses and prepared the figures. Luigi Gastaldo was responsible for the contacts and the recruitment of the patients, as he is the coordinator of the Psychiatric Service and Mental Health Department in the area where the project was realized. Sergio Duca was the reference neurologist at the Koelliker Hospital, responsible for the schedule and the utilization of the MRI and the scan procedures. Tommaso Costa supervised fMRi data analyses. Bruno G. Bara gave a critical review for what concerns the rationale of the used tools and the pragmatic impairment in schizophrenia. Katiuscia Sacco took care and supervised the interpretation of the results and she is responsible for the Discussion section concerning the interpretation of the results.

\section{Acknowledgments}

The research was funded by MIUR PRIN (Progetti di Ricerca di Rilevante Interesse Nazionale) 2017, project "The Interpretative Brain: Understanding and Promoting Pragmatic Abilities across Lifespan and in Mental Illness," project code 201577HA9M.

\section{References}

[1] American Psychiatric Association, Diagnostic and Statistical Manual of Mental Disorders (DSM-5 $\left.{ }^{\circledR}\right)$, American Psychiatric Association Publishing, 2013.

[2] S. C. Levinson, Pragmatics. Cambridge Textbooks in Linguistics, Cambridge University Press, Cambridge, UK, 1983.

[3] A. Moro, V. Bambini, M. Bosia et al., "Detecting syntactic and semantic anomalies in schizophrenia," Neuropsychologia, vol. 79, pp. 147-157, 2015.

[4] C. D. Frith and H. A. Allen, "Language disorders in schizophrenia and their implications for neuropsychology," in Schizophrenia: The Major Issues, P. Bebbington and P. McGuffin, Eds., pp. 172-186, Heinemann Medical Books/Heinemann Professional Publishing, Oxford, UK, 1988.
[5] R. Corcoran, "Inductive reasoning and the understanding of intention in schizophrenia," Cognitive Neuropsychiatry, vol. 8, no. 3, pp. 223-235, 2003.

[6] C. D. Frith and R. Corcoran, "Exploring 'theory of mind' in people with schizophrenia," Psychological Medicine, vol. 26, no. 3, pp. 521-530, 1996.

[7] E. Varga, M. Simon, T. Tényi et al., "Irony comprehension and context processing in schizophrenia during remission-a functional MRI study," Brain and Language, vol. 126, no. 3, pp. 231-242, 2013.

[8] A. Tavano, S. Sponda, F. Fabbro et al., "Specific linguistic and pragmatic deficits in Italian patients with schizophrenia," Schizophrenia Research, vol. 102, no. 1-3, pp. 53-62, 2008.

[9] F. M. Bosco, A. Bono, and B. G. Bara, "Recognition and repair of communicative failures: the interaction between theory of mind and cognitive complexity in schizophrenic patients," Journal of Communication Disorders, vol. 45, no. 3, pp. 181-197, 2012.

[10] T. Tényi, R. Herold, I. M. Szili, and M. Trixler, "Schizophrenics show a failure in the decoding of violations of conversational implicatures," Psychopathology, vol. 35, no. 1, pp. 25-27, 2002.

[11] A. Marini, I. Spoletini, I. A. Rubino et al., "The language of schizophrenia: an analysis of micro and macrolinguistic abilities and their neuropsychological correlates," Schizophrenia Research, vol. 105, no. 1-3, pp. 144-155, 2008.

[12] A. Troisi, G. Spalletta, and A. Pasini, "Non-verbal behaviour deficits in schizophrenia: an ethological study of drug-free patients," Acta Psychiatrica Scandinavica, vol. 97, no. 2, pp. 109$115,1998$.

[13] M. Hoekert, R. S. Kahn, M. Pijnenborg, and A. Aleman, "Impaired recognition and expression of emotional prosody in schizophrenia: review and meta-analysis," Schizophrenia Research, vol. 96, no. 1-3, pp. 135-145, 2007.

[14] K. Sacco, R. Angeleri, F. M. Bosco, L. Colle, D. Mate, and B. G. Bara, "Assessment battery for Communication-ABaCo: a new instrument for the evaluation of pragmatic abilities," Journal of Cognitive Science, vol. 9, no. 2, pp. 111-157, 2008.

[15] R. Angeleri, F. M. Bosco, I. Gabbatore, B. G. Bara, and K. Sacco, "Assessment battery for communication ( $\mathrm{ABaCo})$ : normative data," Behavior Research Methods, vol. 44, no. 3, pp. 845-861, 2012.

[16] F. M. Bosco, R. Angeleri, M. Zuffranieri, B. G. Bara, and K. Sacco, "Assessment battery for communication: development of two equivalent forms," Journal of Communication Disorders, vol. 45 , no. 4, pp. 290-303, 2012.

[17] L. Colle, R. Angeleri, M. Vallana, K. Sacco, B. G. Bara, and F. M. Bosco, "Understanding the communicative impairments in schizophrenia: a preliminary study," Journal of Communication Disorders, vol. 46, no. 3, pp. 294-308, 2013.

[18] B. Binz and M. Brüne, "Pragmatic language abilities, mentalising skills and executive functioning in schizophrenia spectrum disorders," Clinical Neuropsychiatry, vol. 7, pp. 91-99, 2010.

[19] D. Premack and G. Woodruff, "Does the chimpanzee have a theory of mind?" Behavioral and Brain Sciences, vol. 1, no. 4, pp. 515-526, 1978.

[20] M. Brüne, G. Dimaggio, and P. H. Lysaker, "Metacognition and social functioning in schizophrenia: evidence, mechanisms of influence and treatment implications," Current Psychiatry Reviews, vol. 7, no. 3, pp. 239-247, 2011.

[21] F. M. Bosco, L. Colle, S. D. Fazio, A. Bono, S. Ruberti, and M. Tirassa, "Th.o.m.a.s.: an exploratory assessment of theory of mind in schizophrenic subjects," Consciousness and Cognition, vol. 18, no. 1, pp. 306-319, 2009. 
[22] M. Shibata, A. Toyomura, H. Itoh, and J.-I. Abe, "Neural substrates of irony comprehension: a functional MRI study," Brain Research, vol. 1308, pp. 114-123, 2010.

[23] Y. Akimoto, M. Sugiura, Y. Yomogida, C. M. Miyauchi, S. Miyazawa, and R. Kawashima, "Irony comprehension: social conceptual knowledge and emotional response," Human Brain Mapping, vol. 35, no. 4, pp. 1167-1178, 2014.

[24] H. T. Uchiyama, D. N. Saito, H. C. Tanabe et al., "Distinction between the literal and intended meanings of sentences: a functional magnetic resonance imaging study of metaphor and sarcasm," Cortex, vol. 48, no. 5, pp. 563-583, 2012.

[25] M. F. Green, "What are the functional consequences of neurocognitive deficits in schizophrenia?" American Journal of Psychiatry, vol. 153, no. 3, pp. 321-330, 1996.

[26] L. Krabbendam and A. Aleman, "Cognitive rehabilitation in schizophrenia: a quantitative analysis of controlled studies," Psychopharmacology, vol. 169, no. 3-4, pp. 376-382, 2003.

[27] T. Wykes and W. D. Spaulding, "Thinking about the future cognitive remediation therapy-what works and could we do better?" Schizophrenia Bulletin, vol. 37, no. 2, pp. S80-S90, 2011.

[28] D. L. Penn, D. L. Roberts, D. Combs, and A. Sterne, "The development of the social cognition and interaction training program for schizophrenia spectrum disorders," Psychiatric Services, vol. 58, no. 4, pp. 449-451, 2007.

[29] G. Sachs, B. Winklbaur, R. Jagsch et al., "Training of affect recognition (TAR) in schizophrenia-impact on functional outcome," Schizophrenia Research, vol. 138, no. 2-3, pp. 262-267, 2012.

[30] R. Roncone, M. Mazza, I. Frangou et al., "Rehabilitation of theory of mind deficit in schizophrenia: a pilot study of metacognitive strategies in group treatment," Neuropsychological Rehabilitation, vol. 14, no. 4, pp. 421-435, 2004.

[31] S. Moritz, M. Burlon, and T. Woodward, Metacognitive Skill Training for Patients with Schizophrenia. Manual, VanHam Campus Verlag, Hamburg, Germany, 2005.

[32] N. Kayser, Y. Sarfati, C. Besche, and M.-C. Hardy-Baylé, "Elaboration of a rehabilitation method based on a pathogenetic hypothesis of "theory of mind" impairment in schizophrenia," Neuropsychological Rehabilitation, vol. 16, no. 1, pp. 83-95, 2006.

[33] K. T. Mueser, S. I. Pratt, S. J. Bartels, B. Forester, R. Wolfe, and C. Cather, "Neurocognition and social skill in older persons with schizophrenia and major mood disorders: an analysis of gender and diagnosis effects," Journal of Neurolinguistics, vol. 23, no. 3, pp. 297-317, 2010.

[34] I. Gabbatore, K. Sacco, R. Angeleri, M. Zettin, B. G. Bara, and F. M. Bosco, "Cognitive pragmatic treatment: a rehabilitative program for traumatic brain injury individuals," Journal of Head Trauma Rehabilitation, vol. 30, no. 5, pp. E14-E28, 2015.

[35] K. Sacco, I. Gabbatore, E. Geda et al., "Rehabilitation of communicative abilities in patients with a history of TBI: behavioral improvements and cerebral changes in resting-state activity," Frontiers in Behavioral Neuroscience, vol. 10, article no. 48, 2016.

[36] F. M. Bosco, I. Gabbatore, L. Gastaldo, and K. Sacco, "Communicative-pragmatic treatment in schizophrenia: a pilot study," Frontiers in Psychology, vol. 7, article 166, 2016.

[37] A. Meyer-Lindenberg and H. Tost, "Neuroimaging and plasticity in schizophrenia," Restorative Neurology and Neuroscience, vol. 32, no. 1, pp. 119-127, 2014.

[38] P. J. Uhlhaas and W. Singer, "Oscillations and neuronal dynamics in schizophrenia: the search for basic symptoms and translational opportunities," Biological Psychiatry, vol. 77, no. 12, pp. 1001-1009, 2015.
[39] M. J. Hoptman, X.-N. Zuo, P. D. Butler et al., "Amplitude of lowfrequency oscillations in schizophrenia: A Resting State fMRI Study," Schizophrenia Research, vol. 117, no. 1, pp. 13-20, 2010.

[40] J. Zheng, Y. Zhang, X. Guo et al., "Disrupted amplitude of lowfrequency fluctuations in antipsychotic-naïve adolescents with early-onset schizophrenia," Psychiatry Research, vol. 249, pp. 20-26, 2016.

[41] S. L. Fryer, B. J. Roach, K. Wiley, R. L. Loewy, J. M. Ford, and D. H. Mathalon, "Reduced amplitude of low-frequency brain oscillations in the psychosis risk syndrome and early illness Schizophrenia," Neuropsychopharmacology, vol. 41, no. 9, pp. 2388-2398, 2016.

[42] S. L. Fryer, B. J. Roach, J. M. Ford et al., "Relating intrinsic lowfrequency bold cortical oscillations to cognition in schizophrenia," Neuropsychopharmacology, vol. 40, no. 12, pp. 2705-2714, 2015.

[43] S. R. Kay, A. Fiszbein, and L. A. Opler, "The positive and negative syndrome scale (PANSS) for schizophrenia," Schizophrenia Bulletin, vol. 13, no. 2, pp. 261-276, 1987.

[44] M. F. Folstein, S. E. Folstein, and P. R. McHugh, “"Mini-mental state". A practical method for grading the cognitive state of patients for the clinician," Journal of Psychiatric Research, vol. 12, no. 3, pp. 189-198, 1975.

[45] R. Langdon, M. Coltheart, P. B. Ward, and S. V. Catts, "Disturbed communication in schizophrenia: the role of poor pragmatics and poor mind-reading," Psychological Medicine, vol. 32, no. 7, pp. 1273-1284, 2002.

[46] M. Champagne-Lavau and E. Stip, "Pragmatic and executive dysfunction in schizophrenia," Journal of Neurolinguistics, vol. 23, no. 3, pp. 285-296, 2010.

[47] N. Mossaheb, H. N. Aschauer, S. Stoettner et al., "Comprehension of metaphors in patients with schizophrenia-spectrum disorders," Comprehensive Psychiatry, vol. 55, no. 4, pp. 928-937, 2014.

[48] G. M. Caucci and R. J. Kreuz, "Social and paralinguistic cues to sarcasm," Humor, vol. 25, no. 1, pp. 1-22, 2012.

[49] A. Parola, I. Gabbatore, F. M. Bosco et al., "Assessment of pragmatic impairment in right hemisphere damage," Journal of Neurolinguistics, vol. 39, pp. 10-25, 2016.

[50] J. Talairach and P. Tournoux, Co-Planar Stereotaxic Atlas of the Human Brain. 3-Dimensional Proportional System: An Approach to Cerebral Imaging, Thieme, 1988.

[51] Y. Benjamini and Y. Hochberg, "Controlling the false discovery rate: a practical and powerful approach to multiple testing," Journal of the Royal Statistical Society B, vol. 57, pp. 289-300, 1995.

[52] T. T. J. Kircher, D. T. Leube, M. Erb, W. Grodd, and A. M. Rapp, "Neural correlates of metaphor processing in schizophrenia," NeuroImage, vol. 34, no. 1, pp. 281-289, 2007.

[53] A. M. Rapp, D. T. Leube, M. Erb, W. Grodd, and T. T. J. Kircher, "Neural correlates of metaphor processing," Cognitive Brain Research, vol. 20, no. 3, pp. 395-402, 2004.

[54] Z. Eviatar and M. A. Just, "Brain correlates of discourse processing: an fMRI investigation of irony and conventional metaphor comprehension," Neuropsychologia, vol. 44, no. 12, pp. 23482359, 2006.

[55] M. Shibata, J. Abe, A. Terao, and T. Miyamoto, "Neural mechanisms involved in the comprehension of metaphoric and literal sentences: an fMRI study," Brain Research, vol. 1166, pp. 92-102, 2007. 
[56] M. Shibata, J.-I. Abe, A. Terao, and T. Miyamoto, "Neural mechanisms involved in the comprehension of metaphoric and literal sentences: an fMRI study," Brain Research, vol. 1166, no. 1, pp. 92-102, 2007.

[57] R. C. K. Chan, E. Y. H. Chen, and C. W. Law, "Specific executive dysfunction in patients with first-episode medication-naïve schizophrenia," Schizophrenia Research, vol. 82, no. 1, pp. 51-64, 2006.

[58] A. T. Wang, S. S. Lee, M. Sigman, and M. Dapretto, "Developmental changes in the neural basis of interpreting communicative intent," Social Cognitive and Affective Neuroscience, vol. 1, no. 2, pp. 107-121, 2006.

[59] D. A. Robertson, M. A. Gernsbacher, S. J. Guidotti et al., "Functional neuroanatomy of the cognitive process of mapping during discourse comprehension," Psychological Science, vol. 11, no. 3, pp. 255-260, 2000.

[60] E. C. Ferstl and D. Y. Von Cramon, "What does the frontomedian cortex contribute to language processing: coherence or theory of mind?" NeuroImage, vol. 17, no. 3, pp. 1599-1612, 2002.

[61] G. Bottini, R. Corcoran, R. Sterzi et al., "The role of the right hemisphere in the interpretation of figurative aspects of language: a positron emission tomography activation study," Brain, vol. 117, no. 6, pp. 1241-1253, 1994.

[62] V. Goel, B. Gold, S. Kapur, and S. Houle, "The seats of reason? An imaging study of deductive and inductive reasoning," NeuroReport, vol. 8, no. 5, pp. 1305-1310, 1997.

[63] M. E. Raichle, A. M. MacLeod, A. Z. Snyder, W. J. Powers, D. A. Gusnard, and G. L. Shulman, "A default mode of brain function," Proceedings of the National Academy of Sciences of the United States of America, vol. 98, no. 2, pp. 676-682, 2001.

[64] G. R. Kuperberg, P. K. McGuire, E. T. Bullmore et al., "Common and distinct neural substrates for pragmatic, semantic, and syntactic processing of spoken sentences: an fMRI study," Journal of Cognitive Neuroscience, vol. 12, no. 2, pp. 321-341, 2000.

[65] D. Wildgruber, I. Hertrich, A. Riecker et al., "Distinct frontal regions subserve evaluation of linguistic and emotional aspects of speech intonation," Cerebral Cortex, vol. 14, no. 12, pp. 13841389, 2004.

[66] A. M. Rapp, D. E. Mutschler, and M. Erb, "Where in the brain is nonliteral language? A coordinate-based meta-analysis of functional magnetic resonance imaging studies," NeuroImage, vol. 63, no. 1, pp. 600-610, 2012. 

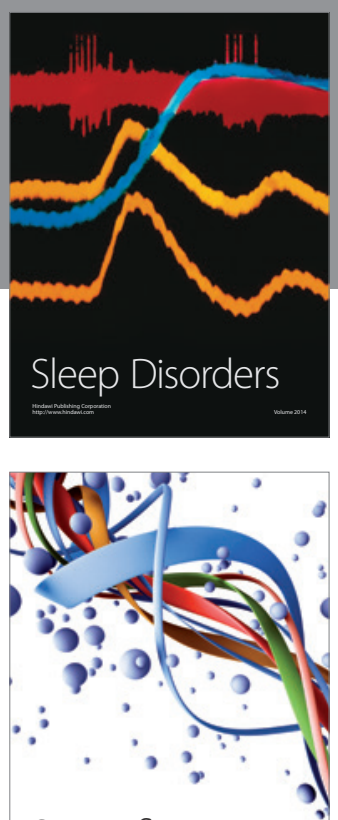

Scientifica
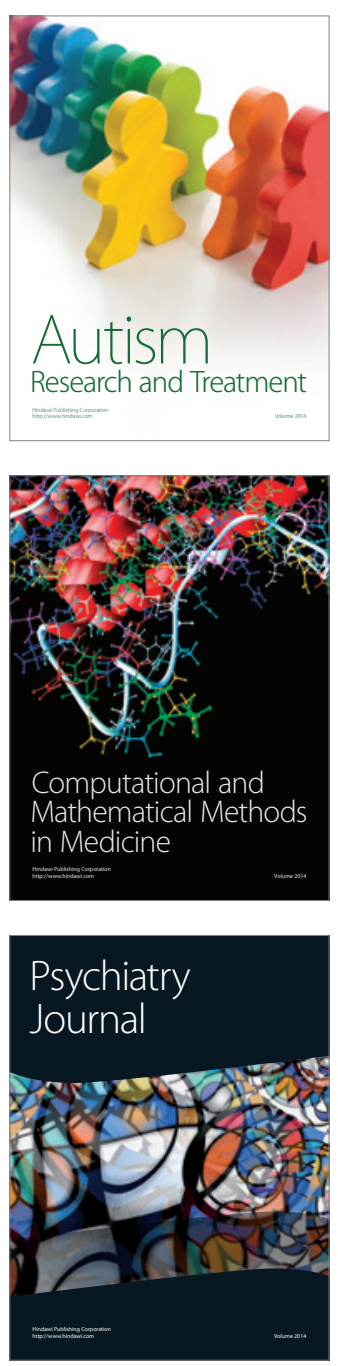
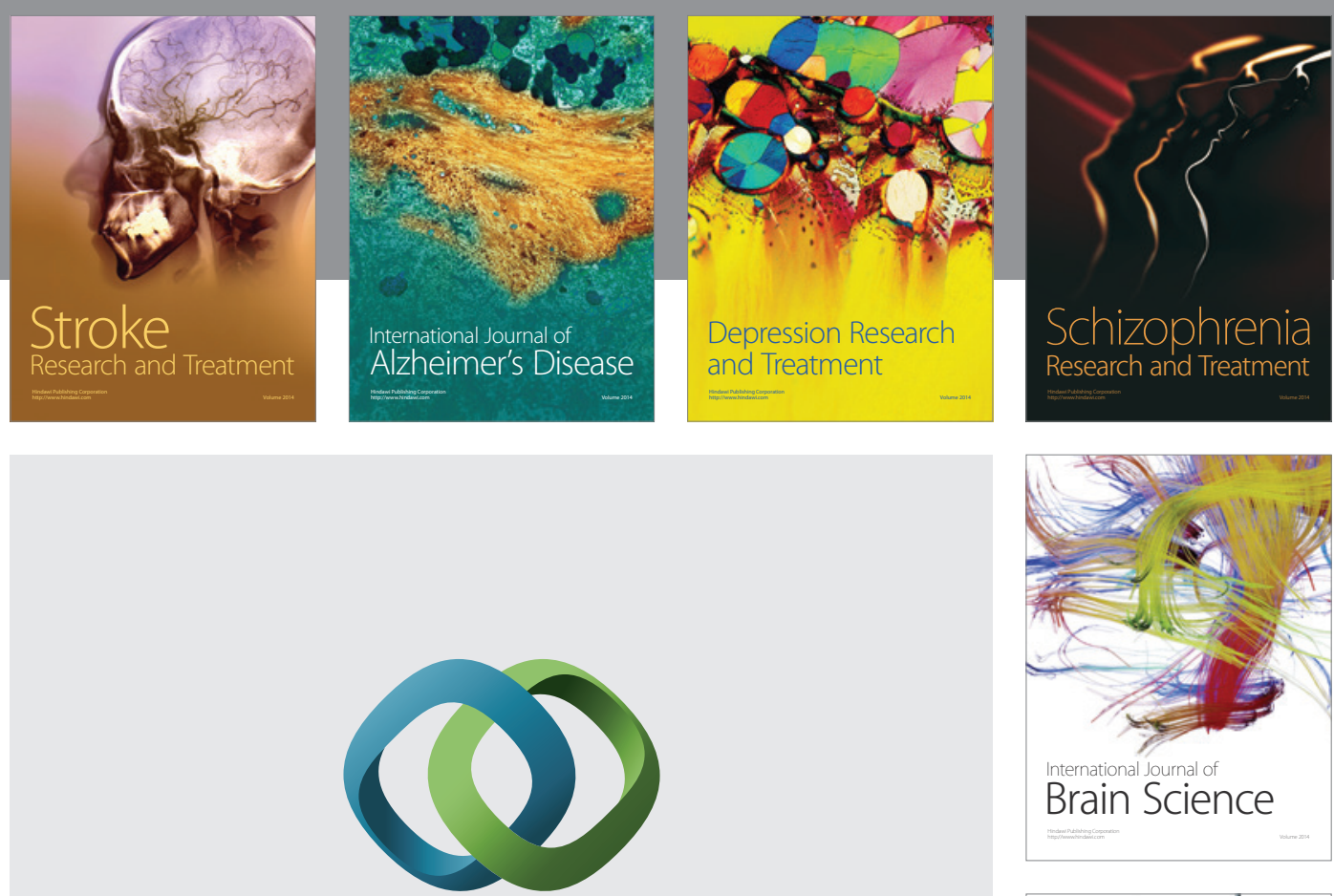

\section{Hindawi}

Submit your manuscripts at

https://www.hindawi.com
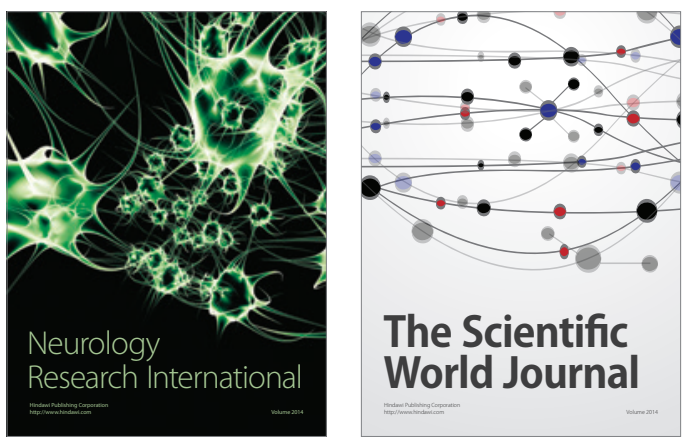

The Scientific World Journal

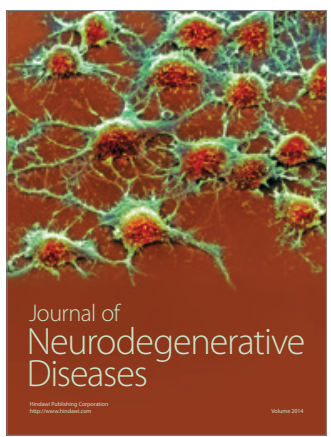

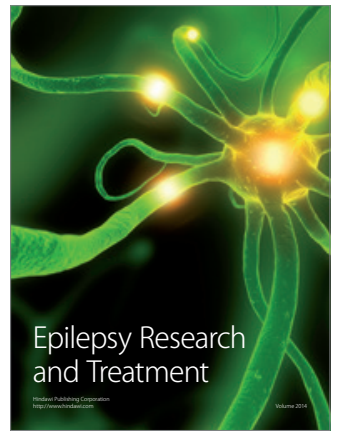

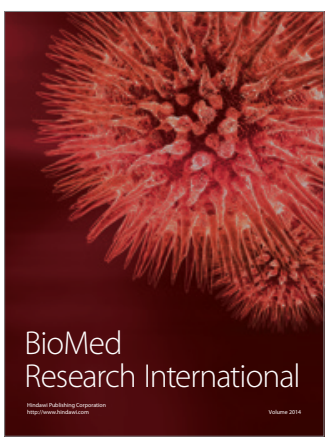

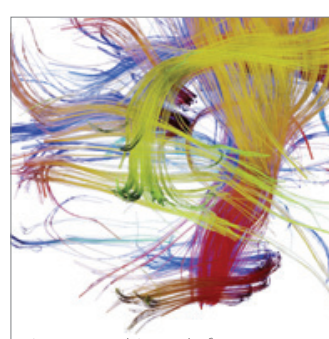

Brain Science

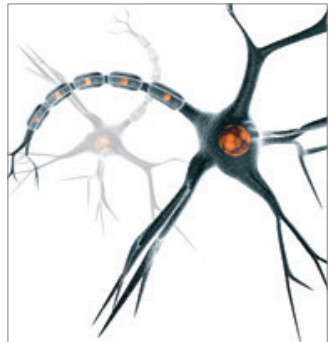

Neural Plasticity
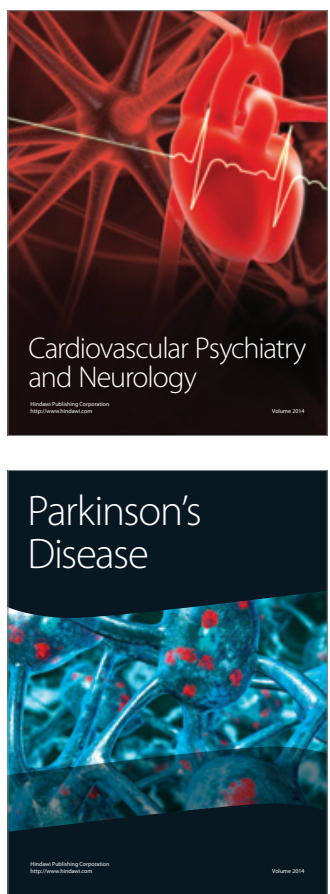